\title{
latrogenic Damage of the Pedicle of Radial Forearm Free Flap Repaired with Super-Microsurgery Techniques: A Case Report
}

\author{
Jonathan Velazquez-Mujica ${ }^{1}$, Hung Chi Chen ${ }^{1}$, Juan Carlos Reyes Cerda ${ }^{2}$ \\ ${ }^{1}$ Department of Plastic Surgery, China Medical University Hospital, Taichung, Taiwan \\ ${ }^{2}$ Department of Plastic Surgery, Clinica Cori, Lima, Peru
}

\section{ARTICLE INFO}

Received : 03 December 2019

Reviewed : 10 December 2019

Accepted : 21 Januari 2020

\section{Keywords:}

Bowen's disease, forearm flap, perforator damage,

supermicrosurgery
*Corresponding author:

Jonathan Velazquez-Mujica

Department of Plastic Surgery, China

Medical University Hospital, Taichung,

Taiwan drjonathan.vm@gmail.com

\section{A BSTRACT}

Introduction: Accidental latrogenic damage of the pedicle or perforators has been frequently reported as a cause of failure of free flaps. Free radial forearm flap helps to cover defects that are not possible to cover with local flaps or skin graft.

Case Presentation: A 91 years old patient with Bowen Disease had multiple actinic keratosis and a history of squamous cell carcinoma over the forehead, which was removed 4 years before. The recurrent tumor was detected and wide excision of the tumor was done. It resulted in a large defect of $8 \times 5.5 \mathrm{~cm}^{2}$ in diameter at the forehead with exposure of bone, therefore, a free radial forearm flap was performed for reconstruction with right superficial temporal artery and vein as recipient's vessel. We observed leakage of blood through the radial artery near to the anastomosis due to iatrogenic damage during flap harvesting.

Conclusions: Nowadays, repairing iatrogenic damage through the main pedicle or perforators of the pedicle is possible with super-microsurgery technique due to the improvement of the skills and smaller sutures avoiding the obstruction of the lumen of the pedicle or perforator. This is considered a salvage procedure instead of harvesting new free flaps and can be useful for all kinds of free flaps.

\section{INTRODUCTION}

Accidental latrogenic damage of pedicle or perforators has been frequently reported as a cause of failure of free flaps and management with a second free flap is strongly recommended [1-3]. Nowadays, the role of supermicrosurgery, and its role in perforating anastomosis and lymphedema surgery, is well known. This was introduced by Isao Koshima et al. [12] that demonstrates the anastomosis in vessels under $0.8 \mathrm{~mm}$. Microsurgery is one of the useful techniques that can help to repair the iatrogenic damage in the main pedicle or perforators and it can be performed with $11-0$ or $12-0$ suture, avoiding the obstruction of the lumen of the vessels, to avoid harvest a second flap.

The radial forearm free flap was one of the earliest free flaps introduced. The skin of the volar surface is thin and pliable, and the cephalic vein is commonly harvested for drainage vein. The radial artery runs in the lateral intermuscular septum that separates the flexor and extensor compartments of the forearm [4]. The key muscle for harvesting is the Brachioradialis and its tendon.

Free radial forearm flap helps to cover defects that are not possible to cover with local flaps or skin graft and is a versatile treatment for frontal defects, with pliable color of the flap skin [5].

\section{CASE PRESENTATION}

A 91 years old patient with Bowen Disease had multiple actinic keratosis and history of squamous cell carcinoma over the forehead, which was removed 4 years earlier, with skin graft for wound closure.

The recurrent tumor was detected and wide excision of the tumor was done. It resulted in a large defect of $4.5 \mathrm{~cm}$ in diameter at the forehead. The specimen was sent for frozen section pathology and shorted margins were still involved by cancer cells. Therefore further excision with the size of $3 \mathrm{~cm}$ was performed around the initial defect (Figure 1,2) with radical excision of the underlying muscle and fascia. It resulted in a large defect of $8 \times 5.5 \mathrm{~cm}^{2}$ with exposure of the frontal bone. The frontal branch of the facial nerve was identified and spared. After confirmation that the margins were free of cancer, we started the reconstruction. A free radial forearm flap was used for reconstruction, to cover the defect with right superficial temporal artery and vein as recipient 
vessel (Figure 3). Additional anastomosis between the cephalic vein and the superciliary vein was done (Figure 4,6).

The Forearm was marked $9.5 \times 5.5 \mathrm{~cm}^{2}$ approximately. The flap was harvested with standard fashion technique under tourniquet and sparing the radial superficial nerve, including the cephalic vein for extra anastomosis. Five minutes before the flap was detached, the tourniquet was off.

After the vascular anastomosis, we observed with the microscopic blood leakage through the radial artery (Figure 5) located near to the anastomosis due to iatrogenic damage during flap harvesting. The hole was $0.7 \mathrm{~mm}$ in diameter of approximately (Figure 6). We put gentle pressure on the hole for a few minutes but the bleeding did not stop, also we tried to apply soft tissue over the surface of the defect on the pedicle and waited for few minutes. Finally, we decided to repair with 11-0 nylon suture with simple primary stitches. The blood flowed through the vascular pedicle smoothly and without obstruction, and the flap survived well. We placed 1 Penrose drain near the anastomosis for hourly lidocaine irrigation.

A split-thickness skin graft harvested from the thigh was used to cover the donor site on the forearm and splint on the dorsal site with a small extension.

The patient stayed at the ward for 10 days after surgery to monitor the flap with doppler and $1 \mathrm{ml}$ of lidocaine $2 \%$ was irrigating the anastomosis for 5 days after surgery. The Penrose was removed on the $9^{\text {th }}$ day

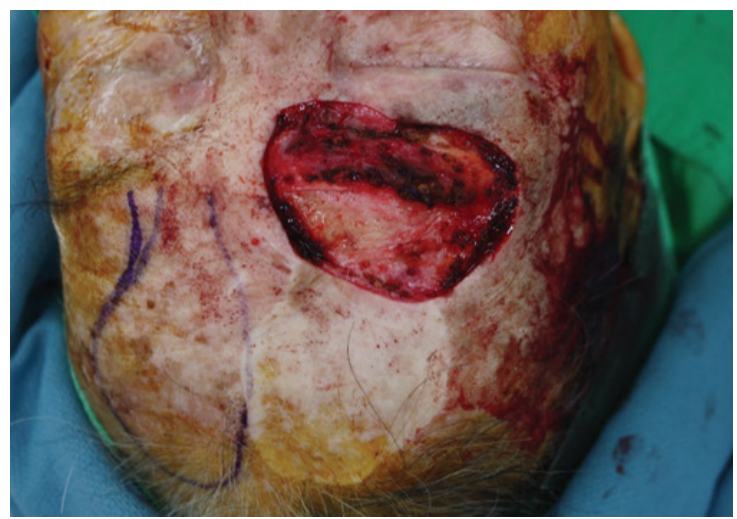

Figure 1. Wide excision of the squamous cell cancer

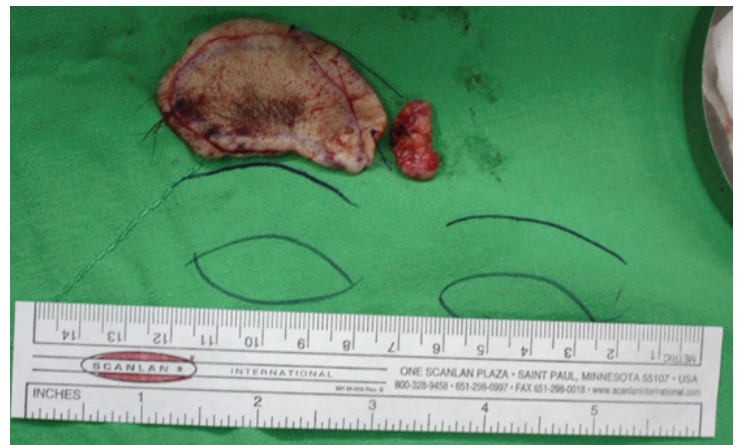

Figure 2. Tissue excision sent to frozen

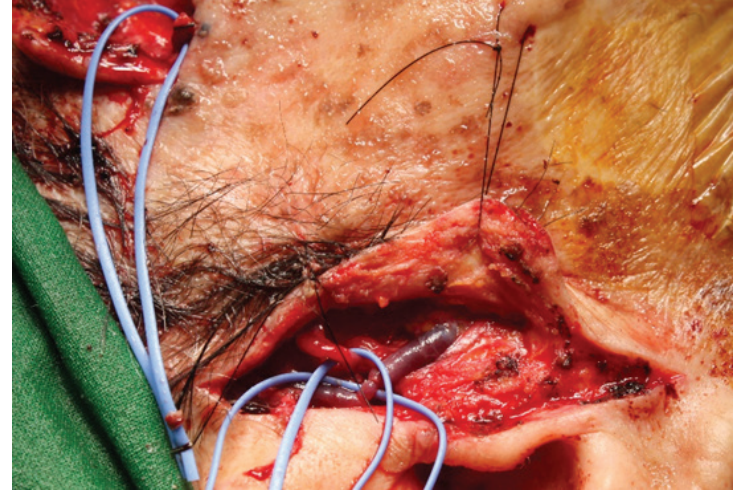

Figure 3. Recipient vessel: Superficial Temporal Artery and Vein

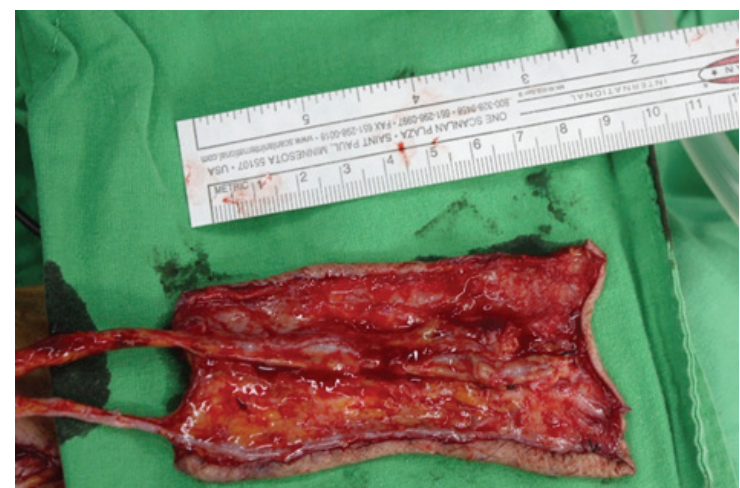

Figure 4. Radial flap

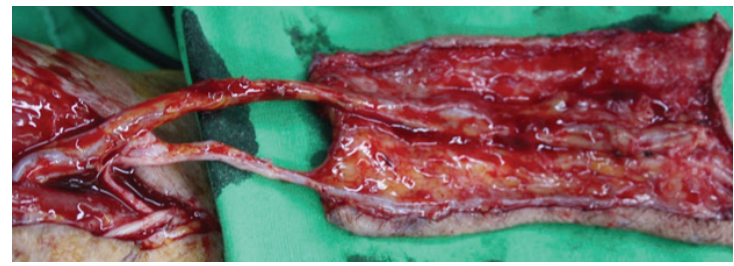

Figure 5. Radial flap with leaking site

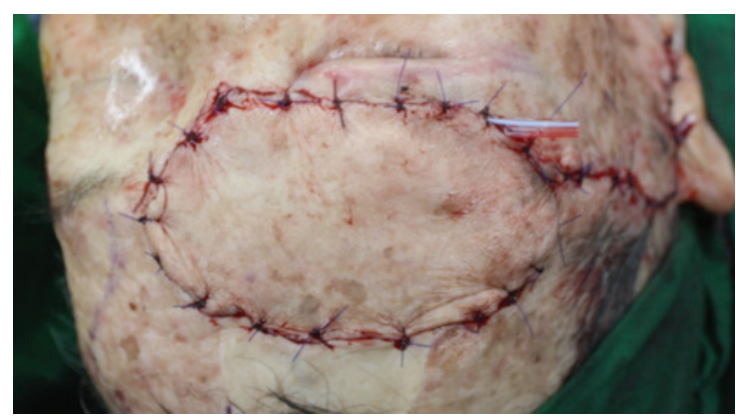

Figure 6. Inseting of radial arm flap

\section{DISCUSSION}

Recurrent cutaneous malignancy is common in Bowen's disease and requires adequate resection to achieve suitable margins characterized for big defects. The radial forearm free flap is a common choice for reconstruction of major front defects, due to its thickness and easy harvesting procedure [6]. In this case, we could 
not use an advance flap due to the size of the wound and a skin graft was not available for bone exposure in some areas. That is why we decided to use the forearm radial free flap.

The radial forearm flap was developed in China in the early 1970s and was published by Yang as a free flap [7]. Acute ischemia after classic flap harvest can occur, however, it is a rare event and sufficient perfusion of the hand can be demonstrated with the Allen test, preoperatively [8]. Only one case of acute ischemia after harvest of the radial artery has been published [9].

The pliability of the flap was also reported in nasal reconstruction by folding the flap, recreating the nasal fossa, avoiding congestion, making a second vein anastomosis, as it was reported by Salibian et al. [10]

While harvesting a free flap, accidental damage to the vein or artery of the vascular pedicle may happen in the training center for junior doctors. However, the damaged vessels can be repaired with fine sutures such as $11-0$ or 12-0 nylon without compromising the blood flow through.

Although regular microvascular anastomosis with 9-0 or 10-0 nylon is not difficult, repair of small damage becomes a challenge by using 11-0 or 12-0 nylon. Care should be taken to not catch the posterior wall of the perforator and it is common to use a second flap as a salvage procedure. The technique is described for ruptures or damage in perforators but can also be applied for the main pedicle to avoid obstruction through the vessel [11].

Supermicrosurgery concept adopted by Koshima et al. [12] allows the anastomosis of smaller caliber vessels and microvascular dissection of vessels ranging from 0.3 to $0.8 \mathrm{~mm}$ in diameter. The small damage in our patient's main pedicle was approximately $0.7 \mathrm{~mm}$, and that is why we decided to use supermicrosurgery to repair, following the same bases for super micro anastomosis [13].

The thin and pliable characteristic of radial forearm free flap is well suited to cover frontal defects and the color matches well including in elderly patients.

\section{CONCLUSIONS}

Nowadays, repairing iatrogenic damage through the main pedicle or perforators of the pedicle is possible with supermicrosurgery technique due to the improvement of the skills and smaller sutures like 11-0 or 12-0, avoiding obstruction of the lumen of the pedicle or perforators. This is considered a salvage procedure instead of harvesting new free flaps and can be useful for all kinds of free flaps, not only radial forearm flap. Developing skills of supermicrosurgery is valuable for all microsurgeons.

\section{DECLARATIONS}

\section{Competing of Interest}

The authors declare no competing interest in this study.

\section{Acknowledgement}

There are no other people, grants or funds that need to be acknowledged in this study.

\section{REFERENCES}

1. Wei FC, Demirkan F, Chen HC, Chuang DC, Shen SH, Lin $\mathrm{CH}$, Cheng $\mathrm{SL}$, et al. The outcome of failed free flaps in head and neck and extremity reconstruction: What is the next in reconstructive ladder?. Plast Reconstr Surg. 2001;108(5):1154-60.

2. Copelli C, Tewfik K, Cassano L, Pederneschi N, Catanzaro S, Manfuso A, Cocchi R. Management of free flap failure in head and neck surgery. Acta Otorhinolaryngol Ital. 2017;37(5):387-392.

3. Ross G, Yla-Kotola TM, Goldstein D, Zhong T, Gilbert R, Irish J, Gullane PJ, et al. Second free flaps in head an neck reconstruction. J Plast Reconstr Aesthet Surg. 2012;65(9):1165-8.

4. Soutar DS, McGregor IA. The Radial Forearm flap in intraoral reconstruction: The experience of 60 consecutive cases. Plast Reconstr Surg. 1986;78(1):1-8.

5. Sweeny L, Eby B, Magnuson JS, Carroll WR, Rosenthal EL. Reconstruction of scalp defects with the radial forearm free flap. Head Neck Oncol. 2012;4:21.

6. Saint-Cyr M, Mujadzic M, Wong C, Hatef D, Lajoie AS, Ronrich RJ. The radial artery pedicle perforator flap: Vascular analysis and clinical implications. Plast Reconstr Surg. 2010;125(5):1469-78.

7. Yang GF, Chen PJ, Gao YZ, Liu XY, Li J, Jiang SX, He SP. Forearm free skin flap transplantation: A report of 56 cases. 1981. Br J Past Surg. 1997;50(3):162-5.

8. Megerle K, Sauerbier M, Germann G. The evolution of the pedicled rafial forearm flap. Hand. 2010;5(1): 37-42.

9. Jones BM, O'Brien CJ. Acute ischaemia of the hand resulting from elevation of a radial forearm flap. $\mathrm{Br}$ J Plast Surg. 1985;38(3):396-7.

10. Salibian AH, Menick FJ, Talley J. Microvascular reconstruction of the nose with the radial forearm flap: A 17 year experience in 47 patients. Plast Reconstr Surg. 2019;144(1):199-210.

11. Kim JT, Youn S, Lee JH, Kim YH. Salvage of free flaps by supermicrosurgical techniques following accidental rupture of the perforator pedicle. J Plast Reconstr Aesthet Surg. 2013;66(7):1010-2. 
12. Koshima I. Microsurgery in the future: Introductin to super-microsurgery and perforators flaps. Presented at the first International Course on perfortor flap and Arterialized skin flaps. Special invited lecture. 1997
13. Isao Koshima, Takumi Yamamoto, Mitsunga Narushima, Makoto Mihara, Tayoko lida, Perofators Flaps and Supermicosurgery. Clin Plast Surg. 2010;37(4):683-9. 